\title{
Adrenocortical Status Predicts the Degree of Age-Related Deficits in Prefrontal Structural Plasticity and Working Memory
}

\author{
Rachel M. Anderson, Andrew K. Birnie, Norah K. Koblesky, Sara A. Romig-Martin, and Jason J. Radley \\ Psychology Department and Neuroscience Program, University of Iowa, Iowa City, Iowa 52242
}

\begin{abstract}
Cognitive decline in aging is marked by considerable variability, with some individuals experiencing significant impairments and others retaining intact functioning. Whereas previous studies have linked elevated hypothalamo-pituitary-adrenal (HPA) axis activity with impaired hippocampal function during aging, the idea has languished regarding whether such differences may underlie the deterioration of other cognitive functions. Here we investigate whether endogenous differences in HPA activity are predictive of age-related impairments in prefrontal structural and behavioral plasticity. Young and aged rats ( 4 and 21 months, respectively) were partitioned into low or high HPA activity, based upon averaged values of corticosterone release from each animal obtained from repeated sampling across a $24 \mathrm{~h}$ period. Pyramidal neurons in the prelimbic area of medial prefrontal cortex were selected for intracellular dye filling, followed by 3D imaging and analysis of dendritic spine morphometry. Aged animals displayed dendritic spine loss and altered geometric characteristics; however, these decrements were largely accounted for by the subgroup bearing elevated corticosterone. Moreover, high adrenocortical activity in aging was associated with downward shifts in frequency distributions for spine head diameter and length, whereas aged animals with low corticosterone showed an upward shift in these indices. Follow-up behavioral experiments revealed that age-related spatial working memory deficits were exacerbated by increased HPA activity. By contrast, variations in HPA activity in young animals failed to impact structural or behavioral plasticity. These data implicate the cumulative exposure to glucocorticoids as a central underlying process in age-related prefrontal impairment and define synaptic features accounting for different trajectories in age-related cognitive function.
\end{abstract}

Key words: corticosterone; HPA axis; medial prefrontal cortex; prelimbic; working memory

\section{Introduction}

Aging is accompanied by a gradual and progressive decline in cognitive processing ability. Nevertheless, some individuals experience significant impairment over time, whereas others retain intact functioning (Rowe and Kahn, 1987; Rapp and Amaral, 1992; Cabeza et al., 2002). Previous studies have linked elevations in the neuroendocrine system responsible for regulating adaptation to stress, the hypothalamo-pituitary-adrenal (HPA) axis and adrenocortical hormones (cortisol in humans, corticosterone [CORT] in rodents), with alterations in hippocampal neurobiology and related behaviors during aging (Landfield et al., 1978; Issa et al., 1990; Sapolsky, 1992; Lupien et al., 1994). Individual differences in HPA activity are programmed by early-life experiences and may be further modified throughout life by severe or

Received April 3, 2014; revised May 5, 2014; accepted May 7, 2014.

Author contributions: R.M.A. and J.J.R. designed research; R.M.A., N.K.K., S.A.R.-M., and J.J.R. performed research; R.M.A., A.K.B., N.K.K., and J.J.R. analyzed data; R.M.A., A.K.B., and J.J.R. wrote the paper.

This work was supported by National Institutes of Health Grant MH-095972 to J.J.R. We thank Alfredo Rodriguez for advice with running the NeuronStudio software and Teresa Treat for consultation with the statistical design and implementation.

The authors declare no competing financial interests.

Correspondence should be addressed to Dr. Jason J. Radley, Department of Psychology, University of lowa, E232 Seashore Hall, lowa City, IA 52242. E-mail: Jason-radley@uiowa.edu.

DOI:10.1523/JNEUROSCI.1385-14.2014

Copyright $\odot 2014$ the authors $\quad 0270-6474 / 14 / 348387-11 \$ 15.00 / 0$ prolonged stressful events (Zhang and Meaney, 2010). Although some consideration has been given to the possibility that individual differences in HPA activity may predict vulnerability to cognitive processes beyond the hippocampus (Lupien et al., 1999; Li et al., 2006; Franz et al., 2011), their underlying mechanisms have yet to be critically examined.

The prefrontal cortex is highly vulnerable to the effects of stress and aging (Holmes and Wellman, 2009; Mizoguchi et al., 2009; Garrido, 2011; Hara et al., 2011; McEwen and Morrison, 2013; Samson and Barnes, 2013). Many of these experiencedependent network alterations in prefrontal functioning can be understood by examining dendritic spines (Goldman-Rakic, 1995; Dickstein et al., 2013; Morrison and Baxter, 2012), as these specializations encompass the vast majority of excitatory synapses made onto cortical pyramidal neurons and represent important sites for synaptic plasticity (Nimchinsky et al., 2002; Holtmaat and Svoboda, 2009). It has been widely documented that pyramidal neurons in medial prefrontal cortex (mPFC) undergo dendritic shortening, spine loss, and are associated with prefrontal functional impairment after prolonged stress and/or exposure to adrenocortical hormones (Wellman, 2001; Liston et al., 2006; Cerqueira et al., 2007; Liu and Aghajanian, 2008; Hains et al., 2009; Barsegyan et al., 2010). If the stress is abated, prefrontal neurons in young animals demonstrate an exceptional restor- 
ative capacity (Radley et al., 2005; Bloss et al., 2010). Aged animals lack such resilience and show deterioration of prefrontal dendritic spine synapses (Peters et al., 2008; Bloss et al., 2011), most notably within subtypes that are thought to result in diminished cognitive functioning (Arnsten et al., 2010; Dumitriu et al., 2010). Although this raises the possibility that the weathering of prefrontal synaptic structure and cognition may result from cumulative exposure of adrenocortical hormones throughout life (McEwen, 1998), an important implication is that variations in HPA activity should account for different functional trajectories evident in aging. Here we characterize HPA neuroendocrine signatures in young and aged rats to interrogate the extent to which elevated adrenocortical output is predictive of age-related impairments in dendritic spine plasticity in MPFC and spatial working memory.

\section{Materials and Methods}

Animals. The animals used in this study were male Sprague Dawley albino rats at ages of 4 and 21 months (designated as young and aged, respectively; Harlan Laboratories). Animals were housed in pairs and maintained on a 12:12 h light/dark cycle (lights on at 0600), with free access to food and water. The health of the aged animals was verified upon arrival from the supplier and monitored regularly by the attending veterinarian to ensure freedom from spontaneous tumors or other overt physiologic or immunologic signs of distress. After 2 weeks of acclimatization in the animal housing facility, rats were habituated to human contact by handling each for $5 \mathrm{~min}$ each day, over at least $7 \mathrm{~d}$ before the initiation of experiments.

Blood collection and radioimmunoassay. Basal adrenocortical activity was measured by obtaining blood samples from the tail vein of rats at 6 time points over a $24 \mathrm{~h}$ period starting at 8:00 A.M. For blood collection, rats were restrained briefly ( $\sim 15-30 \mathrm{~s})$, and a small longitudinal incision was made at the distal tip of the tail with a sterile blade. Blood samples $(\sim 200 \mu \mathrm{l})$ were collected into chilled plastic microfuge tubes containing EDTA and aprotinin, centrifuged, and fractionated for storage of plasma at $-80^{\circ} \mathrm{C}$ until assayed. Plasma CORT was measured without extraction, using an antiserum raised in rabbits against a CORT-BSA conjugate, and ${ }^{125} \mathrm{I}$-CORT-BSA as tracer (MP Biomedicals). Assay sensitivity was 0.8 $\mu \mathrm{g} / \mathrm{dl}$; intra-assay and interassay coefficients of variation were $5 \%$ and $10 \%$, respectively.

Histology and tissue processing. Rats were anesthetized with chloral hydrate $(350 \mathrm{mg} / \mathrm{kg}$, i.p. $)$ and perfused via the ascending aorta with 100 $\mathrm{ml} 1 \%$ PFA and $0.125 \%$ glutaraldehyde in $0.1 \mathrm{M}$ PBS, pH 7.4, followed by $500 \mathrm{ml}$ of $4 \%$ PFA and $0.125 \%$ glutaraldehyde in $0.1 \mathrm{M} \mathrm{PBS}, \mathrm{pH} 7.4$, at a flow rate of $55 \mathrm{ml} / \mathrm{min}$. After postfixation, the pregenual pole of the cortex was sectioned coronally into $250-\mu \mathrm{m}$-thick slabs using an oscillating tissue slicer (VT-1000S, Leica) and stored in $0.1 \mathrm{~m}$ PBS containing $0.1 \%$ sodium azide at $4^{\circ} \mathrm{C}$ until the time of cell loading.

Intracellular dye injections and neuronal reconstructions. The procedures used here are based on previous reports using the same methodology (Radley et al., 2006, 2008). Coronal tissue slabs were treated in the DNA-binding fluorescent stain DAPI (Invitrogen) to distinguish between nuclear lamination patterns that distinguish prelimbic (PL) from other adjacent-lying prefrontal cortical subfields. DAPI-treated sections were mounted on nitrocellulose filter paper and submerged in a tissue culture dish containing $0.1 \mathrm{M}$ PBS and viewed under fluorescence using a fixed-stage microscope (Leica DM5500). Injections of 5\% Lucifer yellow (Invitrogen) were made by iontophoresis through micropipettes (1-2 $\mu \mathrm{m}$ inner diameter) under a DC current of $1-6 \mathrm{nA}$ for $5-10 \mathrm{~min}$. Neurons in layers 2 and 3 of PL were selected for the dye injection procedure based upon the distinguishing cytoarchitectonic features of this region, notably a more densely packed layer 2 and a broader layer 5 relative to adjacent-lying cortical subfields. The general technique for cell filling involved carefully observing the passive diffusion of LY resulting from application of a negligibly small amount of current from the advancing micropipette tip under $40 \times$ magnification; LY diffuses amorphously until hitting a dendritic process or cell body, whereby the dye becomes restricted intracellularly. After several neurons were filled intracellularly, tissue sections were mounted onto glass slides and coverslipped in Vectashield (Vector Laboratories).

Neuronal reconstructions and data analyses were performed by an experimenter unaware of the treatment condition for each animal. Pyramidal neuron dendritic arbors were reconstructed in 3D using a computer-assisted morphometry system consisting of a Leica DM4000R equipped with an Applied Scientific Instrumentation MS-2000 XYZ computer-controlled motorized stage, a QImaging Blue digital camera, a Gateway computer, and morphometry software (MBF Biosciences). Neurons were visualized, and the dendritic tree was reconstructed using a Leica Apochromat $40 \times$ objective with a numerical aperture (NA) of 1.4 and Neurolucida software (MBF Biosciences).

To be considered for analysis, LY-filled PL neurons had to exhibit complete filling of the dendritic tree, as evidenced by well-defined endings. A series of strict criteria were used for inclusion of pyramidal neuron apical and basal dendrites for morphologic analysis. For apical dendrites, the fact that the primary shaft generally coursed parallel, or gently downward from the top surface of the section (i.e., sections were flipped in instances where apical dendrites coursed upward out of the top surface of the section), optimized the probability for retaining complete dendritic arbors. However, because the dye-filling procedure performed in the sections were only $250 \mu \mathrm{m}$ thick, it was virtually impossible to retain an entirely intact apical dendritic arbor with no truncations. Thus, apical dendrites included in the analysis retained intact secondary and tertiary branches, with truncations permitted only in collateral branches that appeared to be nearing the point of termination or deemed unlikely to make any significant bifurcations. PL neurons in layers 2 and 3 were also appreciated to exhibit some qualitative differences; deeper-lying layer 3 neurons possessed apical dendrites with elongated primary dendrites before the first truncation point $(\sim 75-125 \mu \mathrm{m}$; notwithstanding collateral branching), whereas more superficially situated layer 2 neurons contained shorter distances to the first branch point $(\sim 25-75 \mu \mathrm{m}$; e.g., compare images in Figs. 2 and 3). Nevertheless, consideration of these subsets as morphologically distinct subpopulations in ancillary analyses failed to demonstrate any quantitative differences that warranted partitioning them into distinct groupings. For basal dendrites, it was common to retain an average of 1-3 entirely intact arbors for a given LY-filled neuron, such that analyses on intact branches were performed for this category.

Confocal laser scanning microscopy and dendritic spine analysis. Twodimensional renderings for each neuron were obtained using Neurolucida software, and a radial distance of $150 \mu \mathrm{m}$ from the soma was selected as a boundary delineating proximal and distal portions of the dendritic tree. Within these regions, branches were randomly selected for each neuron for an average of 3 segments per neuron and 5 neurons for each animal. The selection criteria for confocal imaging of dendritic segments are based upon previous reports (Radley et al., 2006, 2008): (1) possess a diameter of $<3 \mu \mathrm{m}$, as larger diameter dendrites in PL pyramidal neurons exhibit greater variability in spine density values; (2) reside within a depth of $70 \mu \mathrm{m}$ from the top surface of the section, due to the limited working distance of the optical system; (3) to be either parallel to, or course gently relative to, the coronal surface of the section (i.e., this helps to minimize $z$-axis distortion and facilitate the unambiguous identification of spines); and (4) have no overlap with other branches that would obscure visualization of spines. $z$-Stacks were collected on a Leica SP5 confocal laser-scanning microscope equipped with an argon laser and a $100 \times, 1.4$ NA oil-immersion objective, using voxel dimensions of $0.1 \times$ $0.1 \times 0.1 \mu \mathrm{m}^{3}$. Settings for pinhole size ( 1 airy disc), gain, and offset were optimized initially and then held relatively constant throughout the study to ensure that all images were digitized under similar illumination conditions at a resolution of $512 \times 512$ pixels.

Images were deconvolved with AutoDeblur (Media Cybernetics), and spine analyses were performed using the semiautomated software $\mathrm{Neu}$ ronStudio (Rodriguez et al., 2006; Radley et al., 2008) (http://research. mssm.edu/cnic/tools-ns.html), which analyzes in 3D dendritic length, spine density, and morphometric features (i.e., head/neck diameter, length, subtype) for each dendritic spine. Spines were classified as thin or mushroom if the ratio of the head diameter-to-neck diameter was $>1.1$. 
If their ratio exceeded this value, spines with a maximum head diameter $>0.4 \mu \mathrm{m}$ were classified as mushroom or else were classified as thin. Spines with head-to-neck diameter ratios $<1.1$ were also classified as thin if the ratio of spine length-to-neck diameter was $>2.5$; otherwise, they were classified as stubby. A fourth category, filopodial spines, was considered to have a long and thin shape with no enlargement at the distal tip, was very seldom observed, and was classified as thin. Finally, data readouts from the spine analysis algorithm were visually compared by the experimenter for each optical stack to verify accurate subtype classifications for dendritic spines.

Assessment of prefrontal functionality using delayed alternation. Young and aged rats were first submitted to repeated blood sampling for assessment of basal adrenocortical activity (as above) and given a week to recover while still being handled daily. Animals were then placed on a restricted diet and trained in a prefrontal-dependent spatial working memory task, delayed alternation using a T-maze (Divac, 1971; Ramos et al., 2003). Rats were first habituated to a T maze $(90 \times 65 \mathrm{~cm} ; 40 \mathrm{~cm}$ opaque walls surrounding the perimeter) over a several day period using miniature chocolate chips as a food reward for running to either goal arm in $<60 \mathrm{~s}$. Next, animals were subjected to a forced alternation period of training where they were only rewarded with chocolate after entering the opposite goal arm that they were in previously. Between trials, the maze was wiped clean with $95 \%$ ethanol to prevent olfactory cues from determining choice. After 3 consecutive days of 10 trials/day, animals were tested for spontaneous alternation (i.e., chocolate was present in both goal arms, although rats were only rewarded for entering the opposite arm from the previous trial). The delay between trials was increased until animals could successfully alternate at a $15 \mathrm{~s}$ interval with $>70 \%$ accuracy for 10 trials.

Testing involved 8 trials/day over 6 consecutive days. The delays between each trial were semirandomly varied between 30,60 , or $120 \mathrm{~s}$ (on a given day the same pattern was used for all animals). During delay, rats were placed in the holding cage and the maze was cleaned with $95 \%$ ethanol. The percentage of correct choice alternations made at each delay interval $(30,60$, and $120 \mathrm{~s}$ ) were obtained for each animal, and overall averages were expressed as a function of treatment group.

Statistics. Group data from the CORT radioimmunoassay were compared with a multifactorial ANOVA, followed by pairwise comparisons using Tukey HSD at each time point. Data are expressed as the mean \pm SEM. Data from the dendritic branch and spine morphometric experiments were averaged from each animal (3-4 segments/PL neuron, 5 neurons/animal, 6-7 animals per group) as a function of both age and adrenocortical status. The effects on overall dendritic length, number of branch endings, dendritic spine and subtype densities, and delayed alternation performance at each interval $(30,60$, and $120 \mathrm{~s})$ were compared using a repeated-measures ANOVA, with factors of age (young, aged), adrenocortical status (low, high CORT), and the delay interval as the within-subjects factor. Additional correlational tests were performed for the assessment of whether each dependent measure varied as a function of integrated CORT values for each subject. All pairwise comparisons were made using Tukey HSD, with significance set at $p<0.05$, and data are expressed as mean \pm SEM.

Cumulative distribution differences for certain spine parameters (i.e., mushroom spine head diameter, thin spine head diameter, thin spine length) were evaluated using the Kolmogorov-Smirnov test with MATLAB software (MathWorks). Because mushroom-type spine head diameters were the only subtype to reveal populations shifts as a function of treatment status, data from only these analyses are presented (see Results). Follow-up analyses were performed to determine whether changes in mushroom spine head diameters occurred equally across the entire spectrum of size measurements or were more pronounced in specific subpopulations of spines of this class (e.g., the smallest and largest). Finally, spine parameters (head diameter, length) from all subtypes were pooled, and the 25th and the 75th percentiles, and differences in proportions of spines below the 25th percentile, as well as above the 75th percentile, were examined between aged and young subgroups. The $\chi^{2}$ goodness-of-fit test was used to compare the proportions below the first quartile cutoffs between groups as well as the proportions above the third quartile cutoffs (Radley et al., 2008).
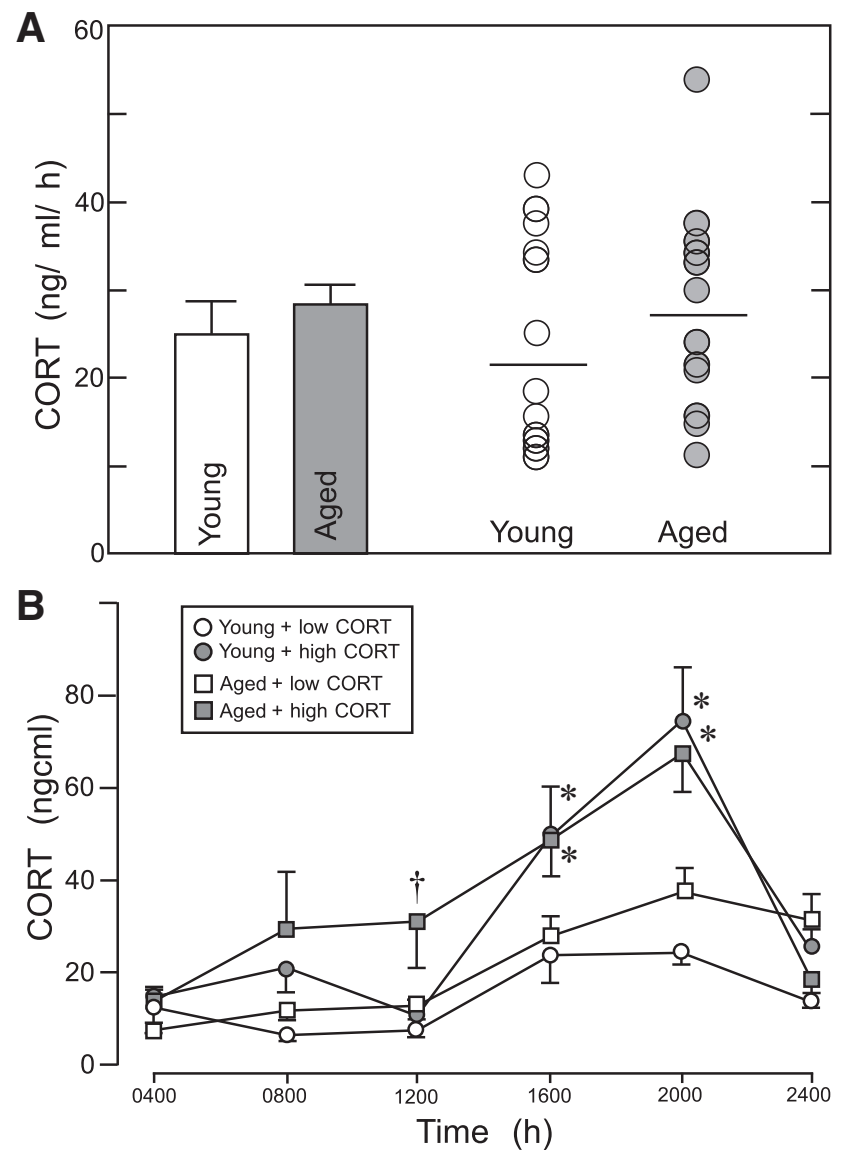

Figure 1. A, Mean + SEM for plasma CORT levels averaged across all six time points sampled (left), and plots of individual values (right). Although young and aged animals did not significantly differ in terms of overall adrenocortical activity, there exists a considerable degree of variability in glucocorticoid secretory output within each group. These differences provided the basis for dividing animals within each age category into subgroupings of high and low adrenocortical activity (horizontal line in each indicates the median value) for the assessment of agerelated structural plasticity in $\mathrm{MPFC}$ as a function of this endocrine index. $\boldsymbol{B}$, Mean \pm SEM plasma CORT levels in young and aged animals as a function of HPA status sampled at $4 \mathrm{~h}$ intervals across the light-dark cycle. ${ }^{*} p<0.05$, significantly different from low CORT animals. $t p<0.05$, significantly different from both young and aged + low CORT subgroups. $n=6-7$ per group.

\section{Results}

\section{Characterization of adrenocortical activity in young and aged rats}

Adrenocortical secretory activity was characterized in 4-monthold and 21-month-old rats across the light-dark cycle. Blood samples were collected from the tail vein of animals starting at $0800 \mathrm{~h}$, and were repeated at $4 \mathrm{~h}$ intervals, through $0400 \mathrm{~h}$ on the following day. For assessment of variation in adrenocortical activity as a function of age, CORT values from all six sampling intervals were averaged to a single value for each animal (Fig. $1 A$ ). Then, young and aged animals possessing plasma CORT levels above and below the median value for each group were selected to represent high and low levels of adrenocortical activity, respectively. The decision to impose a binary classification scheme for these subgroupings, instead of basing dependent measures on absolute values of CORT secretory activity from individual animals, derives from consideration that the former provides a greater degree of measurement reliability and is less sensitive to statistical outliers (Baxter and Gallagher, 1996). 

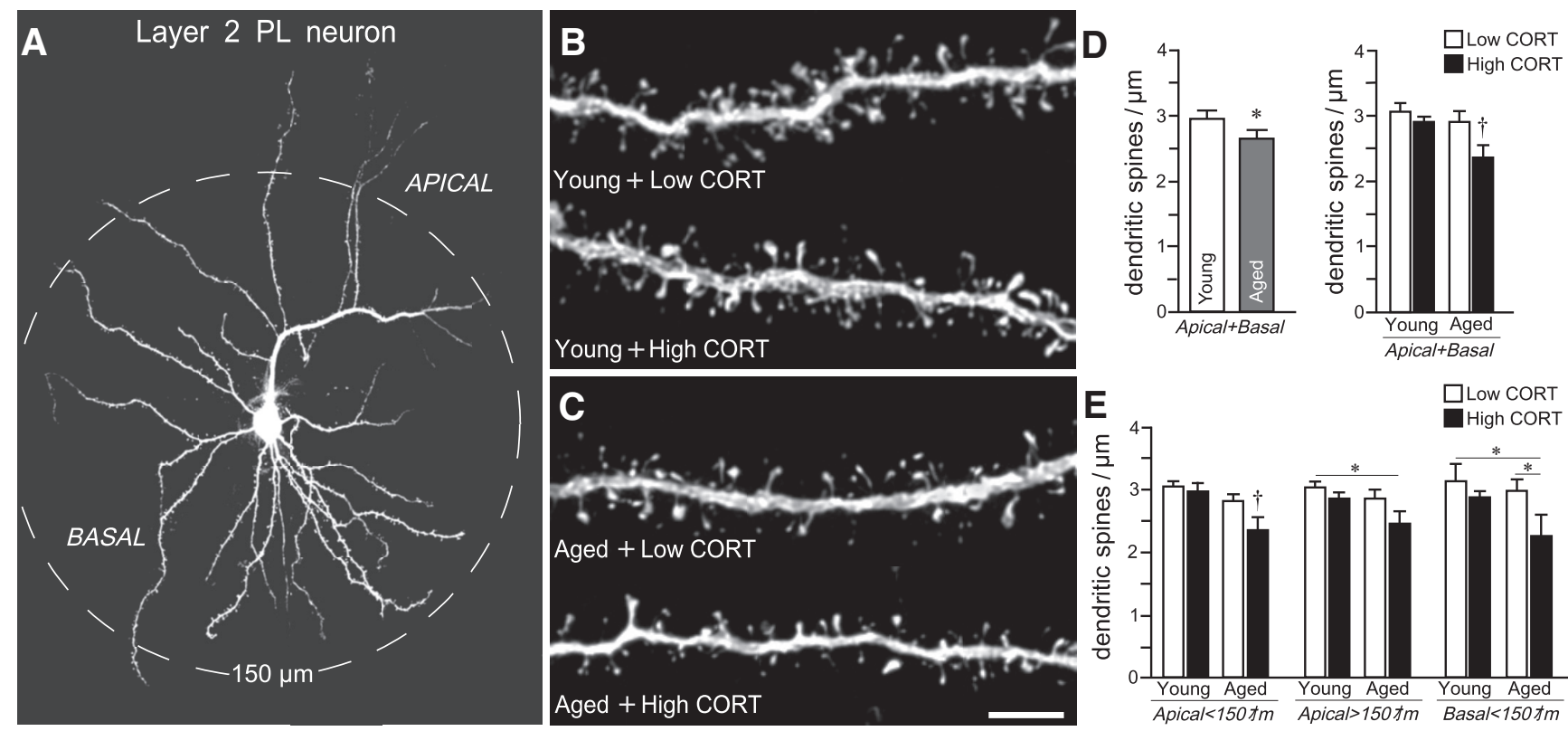

Figure 2. A, Example of a layer 2 PL pyramidal neuron iontophoretically filled with Lucifer yellow. The dashed circle demarcates the $150 \mu \mathrm{m}$ boundary used to partition the dendritic tree for spine analyses. $\boldsymbol{B}, \boldsymbol{C}$, Deconvolved digital images of dendritic segments from different treatment groups. $\boldsymbol{D}$, Mean + SEM of dendritic spine density as a function of treatment group. Disregarding differences in HPA status (left), aged animals $(n=14)$ show a significant reduction in overall spine density relative to young animals $(n=12)$. When aged and young animals are divided according to adrenocortical status (right), the aged + high CORT group exhibits a selective vulnerability for dendritic spine loss. $E$, Regional analyses show that dendrites throughout PL neurons are sensitive to spine loss as a function of aging and HPA status. Data represent mean + SEM for each group and are based on averages from each animal. ${ }^{*} p<0.05$, significantly different for comparisons shown. $t p<0.05$, significantly different from both young and aged + low CORT subgroups. $n=6-7$ per group. Scale bar, $B, C$ (in C), $5 \mu \mathrm{m}$.

Factorial ANOVA (age and CORT status as between-subjects factors; time of day of blood collection as a within-subjects factor) showed main effects for time $\left(F_{(5,110)}=24.30, p<0.001\right)$ and adrenocortical status $\left(F_{(1,22)}=36.18, p<0.001\right)$. Analysis of circadian release patterns in young animals revealed a nadir and peak in CORT secretion at 1200 and $2000 \mathrm{~h}$, respectively (Fig. $1 B$ ). Aged animals bearing low adrenocortical activity generally showed a pattern of CORT release similar to the young + low CORT group, whereas the aged + high CORT animals displayed an HPA secretory pattern distinguished by a failure to reach the nadir at $1200 \mathrm{~h}$ relative to all three of the other groups (2.5-fold higher; $p<0.05$ for each; Fig. 1B). Postmortem measurement of adrenal weights also revealed hypertrophy within both aged and young rats bearing high CORT animals with respect to low CORT groups (age: $F_{(1,22)}=5.32, p=0.03$; CORT status: $F_{(1,22)}=19.20$, $p<0.001$; interaction: $F_{(1,22)}=2.84, p=0.10$; mean \pm SEM: young + low CORT $=10.4 \pm 0.3 \mu \mathrm{g} / \mathrm{g}$; young + high CORT $=$ $11.8 \pm 0.6 \mu \mathrm{g} / \mathrm{g} ;$ aged + low CORT $=11.0 \pm 0.3 \mu \mathrm{g} / \mathrm{g}$; aged + high CORT $=13.5 \pm 0.2 \mu \mathrm{g} / \mathrm{g}$ ).

Aging and adrenocortical status contribute to dendritic spine loss in MPFC

Dendritic spine density

Individual neurons in layer $2 / 3$ pyramidal neurons of the PL cortical subfield of mPFC were selected for intracellular injection of the fluorescent dye Lucifer yellow in young and aged rats that had been previously characterized for basal CORT activity. Different regions of the dendritic tree $(<150 \mu \mathrm{m}$ apical, $>150 \mu \mathrm{m}$ apical, $<150 \mu \mathrm{m}$ basal) were selected for high-resolution confocal laser scanning microscopic imaging of dendritic segments (Fig. $2 A-C$ ). Digital renderings ( $z$-stacks) of dendritic segments made in 3D were deconvolved, followed by the analysis of spine density and morphology using the semiautomated software $\mathrm{Neu}$ ronStudio (Rodriguez et al., 2006; Radley et al., 2008) (Fig. 4A,B).
In this analysis, a total of 406 dendritic segments from 92 fluorescent dye-labeled PL neurons were analyzed for spine density and morphometric analysis (199 young, 207 old), giving a total of 31,176 and 28,418 dendritic spines in young and aged animals, respectively.

We observed an $11 \%$ decrease in overall dendritic spine density in PL neurons in aged relative to young animals (Fig. 2D). Comparisons made between young and aged groups in the context of low and high HPA activity revealed main effects of age $\left(F_{(1,22)}=9.29, p=0.006\right)$, adrenocortical status $\left(F_{(1,22)}=9.14\right.$, $p=0.006)$, and no interaction between these measures $\left(F_{(1,22)}=\right.$ $2.69, p=0.12$ ). Aged animals bearing high CORT levels (i.e., aged + high CORT) displayed 20\% reductions in spine density relative to young subgroups and aged + low CORT animals $(p<$ 0.05 for each; Fig. 2D). By contrast, aged animals with low CORT levels did not show any reduction in spine density relative to either low or high CORT subgroups of young animals ( $p=0.75$ and $p=0.99$, respectively). Comparisons made within different regions of the dendritic tree revealed the same downward trend of spine density in proximal apical dendrites in the aged + high CORT group or rats, showing $21 \%$ reductions in spine density relative to young low and high CORT groups, respectively $(p<$ 0.05 for each; Fig. $2 E$ ). Some attrition of spines, albeit less prominent, was evident in aged + high CORT animals in both distal apical $(>150 \mu \mathrm{m})$ and basal aspects of the dendritic tree (Fig. 2E).

In a follow-up analysis, adrenocortical status was plotted as a function of dendritic spine loss in PL neurons for young and aged groups. Despite the existence of clear group differences between aged + low and high CORT groupings, no reliable correlation between these indices was noted $(r=-0.46, p=0.30)$, whereas the analysis of young animals yielded a slightly more reliable tendency toward variations in adrenocortical activity and PL spine density $(r=-0.68, p=0.10)$. 

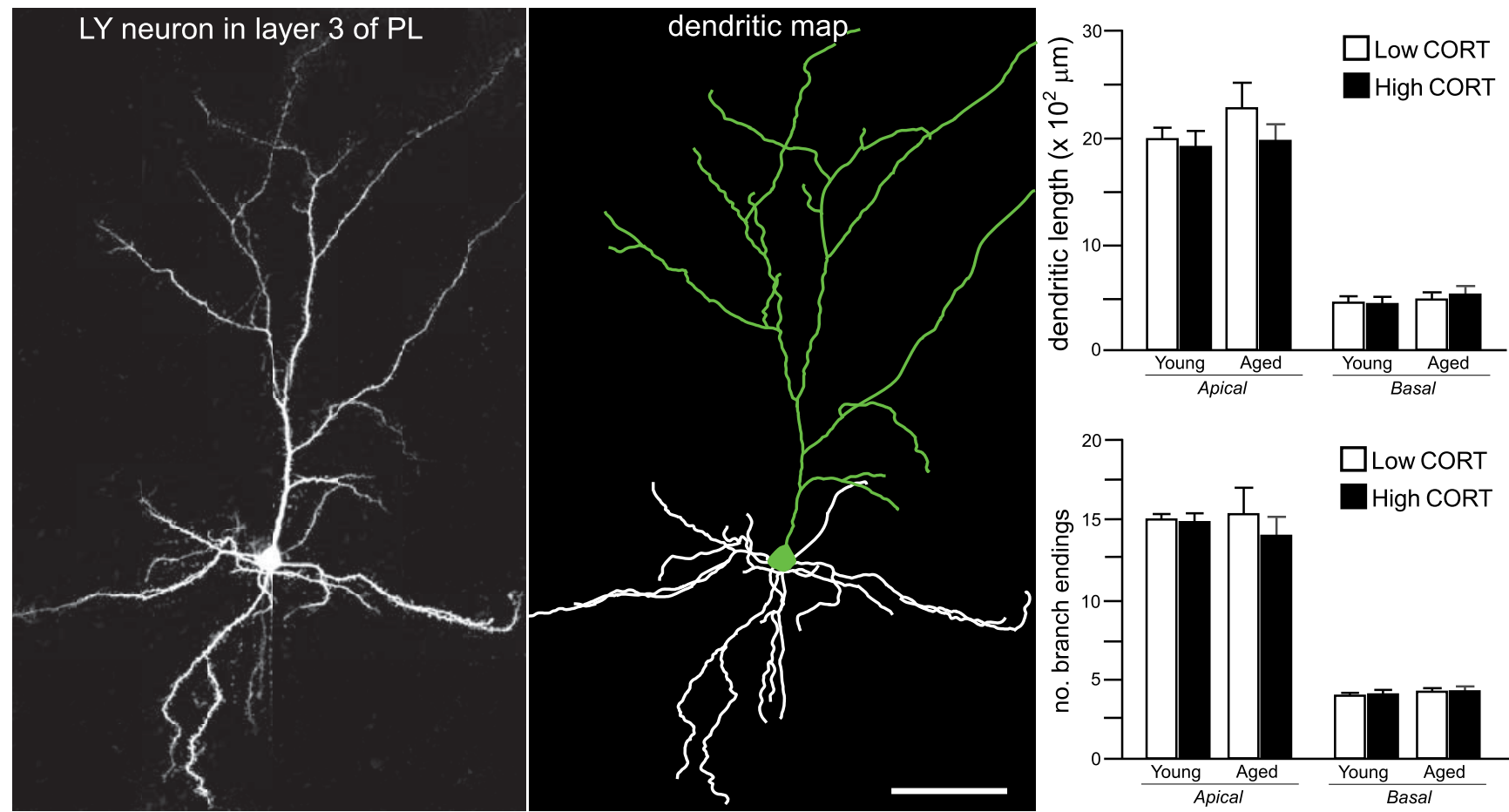

Figure 3. Top, Example neuron in layer 3 of PL that was iontophoretically filled (left), and the rendering of its dendritic tree (right) using computer-assisted morphometry. The apical dendritic tree (green) is pointing upward, and basal dendrites (white) radiate from the opposite pole of the soma. Bottom, Histograms for dendritic length and number of branch endings for apical and basal dendrites. Aging or HPA status failed to result in any significant decreases in the dendritic indices examined. Data represent mean + SEM for each index and are based on overall averages from each animal (i.e., $n=6-7$ animals/group; $n=1$ arbor/neuron; $n=5$ neurons/animal). Scale bar, $75 \mu \mathrm{m}$.

\section{Dendritic arborization patterns}

Given that chronic stress and exogenously administered CORT are known to induce apical dendritic atrophy in mPFC pyramidal neurons (Wellman, 2001; Radley et al., 2004; Cerqueira et al., 2007; Liu and Aghajanian, 2008), we examined dendritic arborization patterns (overall length, branch number) as a function of age and adrenocortical status in the same PL neurons analyzed for alterations in spine plasticity (Fig. 3). A two-way ANOVA design was implemented as above, with age and CORT status as the treatment variables. With regard to apical dendrites, there were no significant main effects or interactions for total length (age status: $F_{(1,19)}=1.75, p=0.20$; CORT status: $F_{(1,19)}=1.81$, $p=0.20$; interaction: $\left.F_{(1,19)}=0.96 ; p=0.34\right)$, or number of branch endings (age status: $F_{(1,19)}=0.40, p=0.85$; CORT status: $F_{(1,19)}=0.63, p=0.44$; interaction: $F_{(1,19)}=0.48 ; p=0.50$ ) (Fig. 3 , bottom). Basal dendritic measures of length (age status: $F_{(1,19)}=2.87, p=0.11$; CORT status: $F_{(1,19)}=0.44, p=0.52$; interaction: $\left.F_{(1,19)}=0.05 ; p=0.83\right)$, and the number of branch endings (age status: $F_{(1,19)}=0.35, p=0.56$; CORT status: $F_{(1,19)}=0.01, p=0.91$; interaction: $\left.F_{(1,19)}=0.03 ; p=0.87\right)$ also failed to reveal any significant differences. These data suggest that dendritic arbors remain relatively resistant to such age-related alterations, suggesting neither a homeostatic response of increased dendritic growth that could compensate for spine synaptic compromise nor further spine loss that could be compounded by dendritic shortening.

\section{Interactive effects of age and HPA status on PL dendritic spine morphology}

Several previous studies have shown that age-related dendritic spine loss in the prefrontal cortex is most prominent within thin subtypes (Dumitriu et al., 2010; Bloss et al., 2011). Thin spines are largely representative of the immature excitatory synaptic popu- lation in cortical pyramidal neurons, exhibiting high rates of turnover compared with large spines (Matsuzaki et al., 2001; Holtmaat et al., 2005), and have decreased rates of turnover after prolonged glucocorticoid exposure (Liston and Gan, 2011). Thus, we addressed the possibility that age-related decreases in thin spine subtypes in PL may be exaggerated in animals presenting elevated adrenocortical activity. Spine morphometric features were delineated from high-resolution optical stacks of dendritic segments in fluorescent dye-filled pyramidal neurons using NeuronStudio (Rodriguez et al., 2006; Radley et al., 2008) (Fig. 4A,B). It has been shown that this method of analysis produces spine density values and morphometric indices similar to EM analytic estimates in adult cortical neurons and is substantially less prone to the population and classification sampling errors common in Golgi-based analytic approaches (Dumitriu et al., 2010).

Two-way ANOVA revealed main effects of age $\left(F_{(1,22)}=6.28\right.$, $p=0.02)$, adrenocortical status $\left(F_{(1,22)}=6.43, p=0.02\right)$, and an interaction $\left(F_{(1,22)}=5.41, p=0.03\right)$ on thin spine density. Post hoc comparisons revealed a significant decrease (by $21 \%$ ) of thin spines between aged + high CORT animals relative to the other three groups ( $p=0.01$ for each; Fig. $4 C$ ). Regional analyses of thin spine density highlighted age-related losses in proximal aspects of the apical dendritic tree, with aged + high CORT animals showing a $26 \%$ decrement compared with all three groups $(p<$ 0.05 for each; Fig. $4 C$ ). Furthermore, some measure of thin spine loss was also noted in basal dendrites in aged + high CORT animals (Fig. 4C). Plots of individual values from young and aged animals failed to demonstrate a reliable inverse correlation between adrenocortical activity relative to thin spine density in PL neurons (young: $r=-0.49, p=0.26$; aged: $r=$ $-0.35, p=0.44)$. 

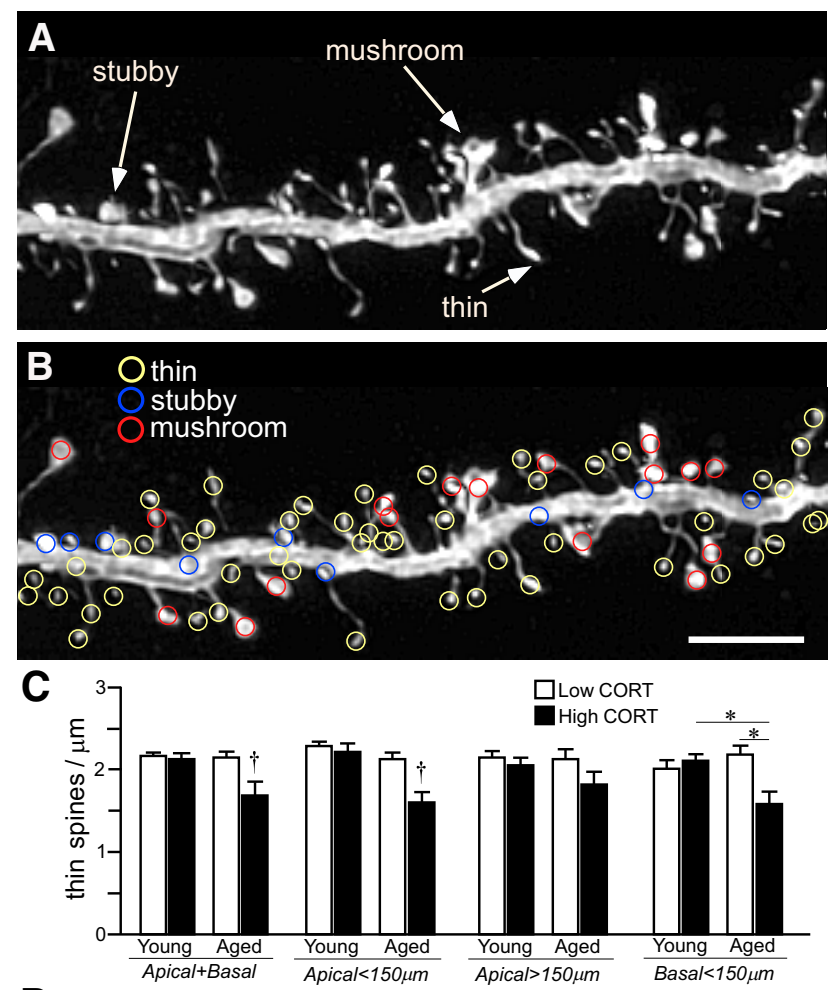

D

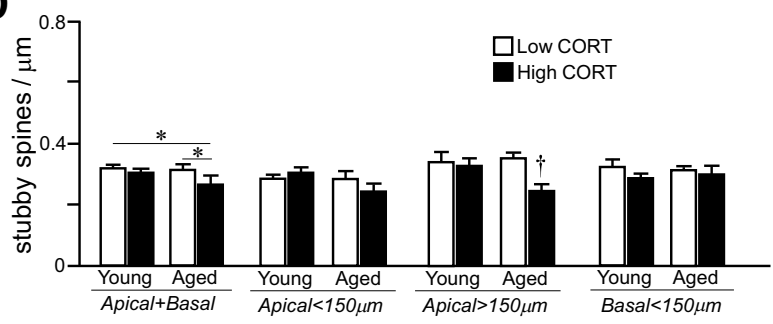

E

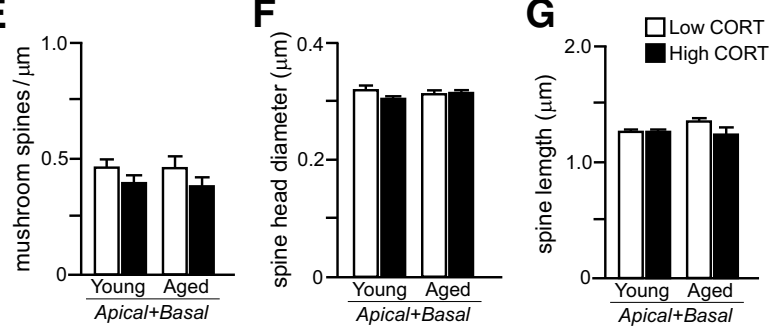

Figure 4. $\quad A$, Example of high-resolution deconvolved optical z-stack of a dendritic segment used for spine analysis with NeuronStudio software. $\boldsymbol{B}$, Open colored circles represent spine subtypes based upon user-defined parameters in the software (see Materials and Methods). Histograms represent the effects of aging and adrenocortical status on thin $(\boldsymbol{C})$, stubby $(\boldsymbol{D})$, mushroom $(\boldsymbol{E})$, spine density, and (for all three subtypes) spine head diameter $(\boldsymbol{F})$ and length $(\boldsymbol{G})$. Aged animals bearing high adrenocortical activity showed selective losses in thin spines and, to a lesser extent, stubby spines in overall measures throughout the apical and basal dendritic tree. ${ }^{*} p<0.05$, significantly different for comparison shown. $\uparrow p<0.05$, significantly different from both young and aged + low CORT subgroups. $n=6-7$ per group. Scale bar, both images, $5 \mu \mathrm{m}$.

Although the functional implications of stubby spines are less well understood, the available evidence suggests that this subtype reflects a distinct subpopulation of immature excitatory synapses from thin spines (Boyer et al., 1998; Petrak et al., 2005; Christoffel et al., 2011). In this analysis, main effects on overall stubby spine density were only noted for adrenocortical status $\left(F_{(1,22)}=9.19\right.$; $p=0.006)$, however, not for age $\left(F_{(1,22)}=3.95 ; p=0.06\right)$ or interaction between these variables $\left(F_{(1,22)}=3.70 ; p=0.07\right)$.
Comparisons relative to aged + high CORT animals revealed some diminution in overall measures of stubby spine density compared with both young + low and aged + low CORT groups ( $p=0.01$ for each; $p=0.051$ compared with young + high CORT group; Fig. 4D). In distal apical dendrites, aged animals bearing high HPA activity were selectively vulnerable to stubby spine loss compared with the other three groups (by 29\%; $p<$ 0.05 for each; Fig. $4 D$ ). Correlation of individual values for stubby spines as a function of CORT levels did not reveal any significant inverse relationship within young $(r=-0.26, p=0.57)$ or aged groups $(r=-0.58, p=0.17)$.

Mushroom spine densities were analyzed as a function of treatment status. No main effects of age or HPA status were noted to influence mushroom spine density in PL neurons (Fig. 4E), nor were any trends evident within apical and basal dendritic subregions. Moreover, no group differences were observed in spine head diameter or spine length (i.e., across all spine subtypes) as a function of treatment group (Fig. $4 F, G$ ). Nevertheless, as recent evidence supports the idea that large volume/mushroom spine subtypes in cortical pyramidal neurons may undergo shrinkage in response to elevated glucocorticoids or chronic stress (Liston and Gan, 2011; Tanokashira et al., 2012; Radley et al., 2013), we examined population shifts in mushroom spine head diameter as a function of age and HPA status. In these analyses, mushroom spines from both young subgroups were treated as a single population because their frequency plots were statistically virtually indistinguishable from one another (Kolmogorov-Smirnov test; $p=0.8$; Fig. $5 A$ ). Cumulative frequencies for mushroom spine head diameter were significantly shifted to the left in the aged + high CORT group compared with young animals (Kolmogorov-Smirnov test, $p<0.0001$ ) (Fig. 5B). By contrast, aged rats with low adrenocortical activity display a rightward shift in the cumulative frequency distribution for mushroom head diameter relative to young animals (Kolmogorov-Smirnov test, $p<0.00001$; Fig. $5 C$ ). Furthermore, examination of relative frequency distributions revealed a greater degree of variability in mushroom spine head diameters in aged relative to young subgroups of animals (Fig. 5D-F). Thus, the leftward shift of the aged + high CORT group implicates prolonged exposure to high glucocorticoid levels as a possible mechanism for mushroom spine shrinkage, whereas the rightward shift suggests that lower levels CORT during aging may be permissive for greater stability in mature spine subtypes.

Finally, to determine whether aging and adrenocortical status produce shifts throughout the entire dendritic spine population in PL neurons, relative frequency distributions were analyzed for spine head diameter and length without regard to subtype. The proportion of spines bearing head diameter or length in the upper and lower quartile of aged + high CORT and aged + low CORT groups were compared with the overall population (Table 1). Aged + high CORT animals displayed a greater proportion of spines with head diameters in the lower quartile and a smaller proportion of long spines in the upper quartile $(p<0.01$ for each, $\chi^{2}$ goodness-of-fit test for comparison of proportions). By contrast, aged animals bearing low adrenocortical activity displayed a greater proportion of spine head diameters in the upper quartile, whereas spine length showed an overall rightward shift, inclusive of a smaller proportion of short spines and a greater proportion of elongated spines $\left(p<0.01\right.$ for each, $\chi^{2}$ test; Table 1). Overall, these patterns suggest that elevated CORT levels during aging produce downward shifts in dendritic spine size and length in PL, whereas age-matched counterparts with low adrenocortical activity display upward shifts in these indices. 
A

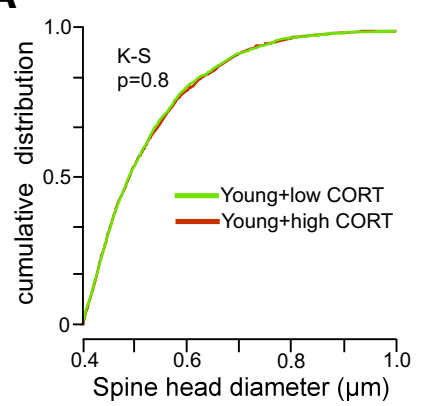

B

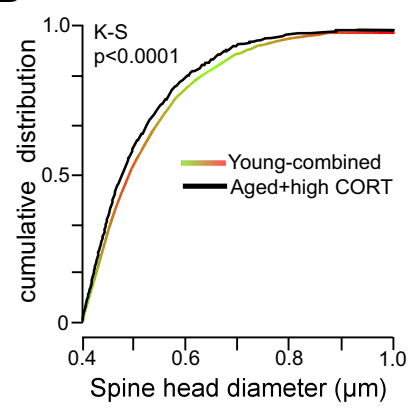

C

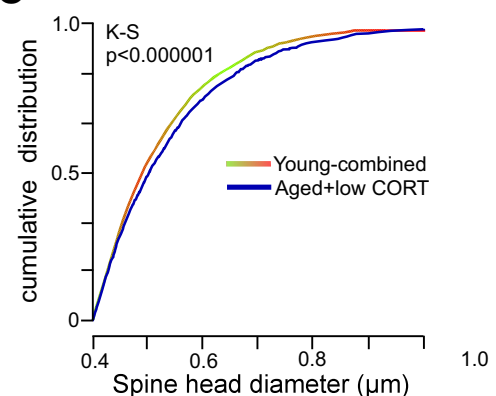

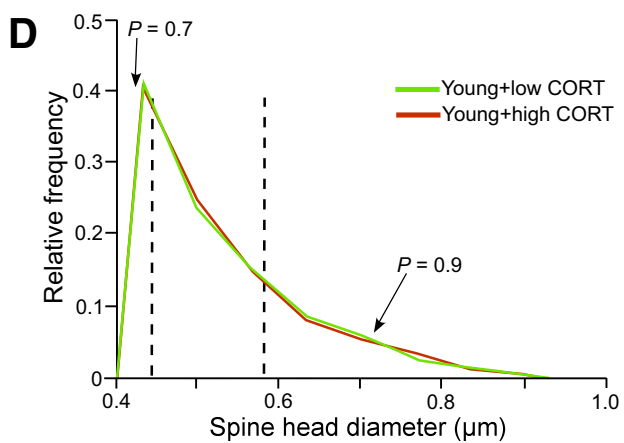
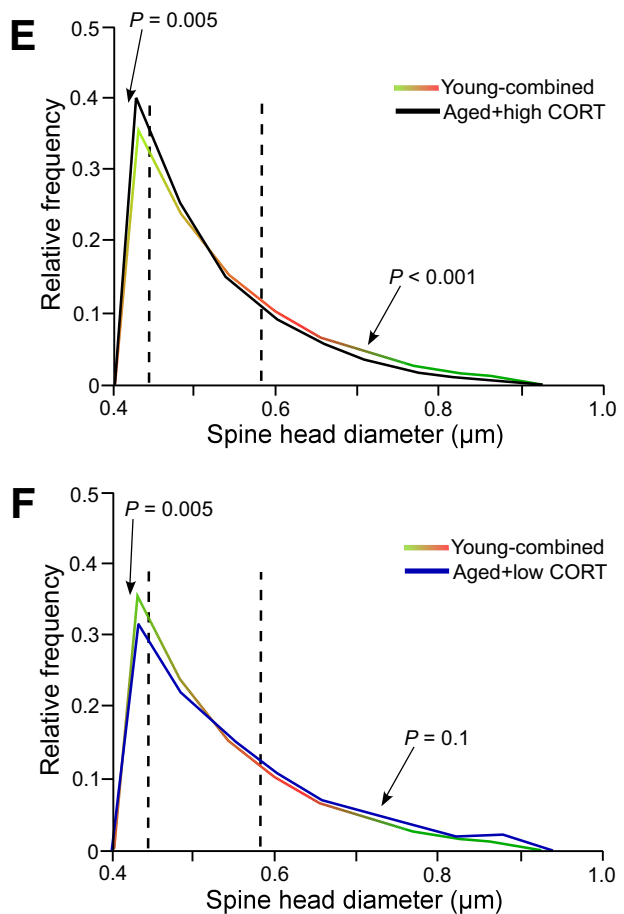

Figure 5. $A-C$, Cumulative frequency distributions of mushroom spine head diameters in PL neurons in young and aged subgroups. $\boldsymbol{A}$, Comparisons between low and high CORT subgroups in young animals revealed no differences between these distributions, thus providing the rationale for treatment as one group for subsequent comparisons. $\boldsymbol{B}$, The aged + high CORT group shows a leftward shift (i.e., decrease) in mushroom spine head diameter relative to young animals, whereas ( $\boldsymbol{C}$ aged + Iow CORT animals for this index show a cumulative frequency that is right-shifted (i.e., increased) relative to young animals, suggesting a mechanism leading to enlargement of mushroom spines relative to both young groups and aged + high CORT animals. K-S, Kolmogorov-Smirnov test. $\boldsymbol{D}-\boldsymbol{F}$, Frequency distributions for mushroom spine head diameter in PL pyramidal neurons in young and aged animals. The dashed vertical lines in each histogram indicate the 25th and 75th percentiles of the entire spine population. D, Comparisons between low and CORT subgroups in young animals. Because there were no differences between these distributions, subsequent analyses entailed combining these subgroups into one overall population. $\boldsymbol{E}$, Comparisons between both young subgroups pooled together and aged + high CORT animals. Aged + high CORT animals show a shift in distribution toward a greater number of spines with small head diameters (lower quartile) and fewer spines with large head diameters (upper quartile) relative to young animals. $\boldsymbol{F}$, Comparisons between both young subgroups pooled together and aged + low CORT animals. Aged + low CORT animals show a shift in distribution toward a greater number of spines with large head diameters (upper quartile) and fewer spines with smaller head diameters (lower quartile) relative to young animals. $p$ values were obtained from the $\chi^{2}$ test for comparison of proportions of each distribution below or above the first or third quartile, respectively.

\section{Interactive effects of age and HPA status on spatial working memory}

Given that aging and HPA status interact to induce regressive structural plasticity in PL neurons, we interrogated whether aged animals with high CORT also show a selective vulnerability to prefrontal cognitive impairment. Separate groups of young adult $(n=10)$ and aged $(n=10)$ male Sprague Dawley rats were assayed for basal adrenocortical function and partitioned into low and high subgroups for CORT activity as described above (Fig. 6). Postmortem measurement of adrenal-to-body weight ratio in this cohort of animals also confirmed that rats with high adrenocortical status displayed a significant degree of adrenal hypertrophy, regardless of age (age: $F_{(1,16)}=1.23, p=0.28$; CORT status: $F_{(1,16)}=$ 15.08, $p=0.001$; interaction: $F_{(1,16)}=1.23$, $p=0.28)$. Furthermore, the absolute values of adrenal-to-body weight ratios were comparable across cohorts (mean \pm SEM: young + low CORT $=10.4 \pm 0.3$ $\mu \mathrm{g} / \mathrm{g} ;$ young + high CORT $=11.5 \pm 0.4$ $\mu \mathrm{g} / \mathrm{g}$; aged + low CORT $=10.3 \pm 0.5 \mu \mathrm{g} / \mathrm{g}$; aged + high CORT $=12.1 \pm 0.2 \mu \mathrm{g} / \mathrm{g}$ ).

Animals were trained in a delayed alternation task using a T maze, which is dependent upon intact mPFC function (Divac, 1971; Ramos et al., 2003) (Fig. $7 A)$. The number of training sessions required for each animal to reach an equivalent level of performance was used as a measure of acquisition (i.e., $>70 \%$ choice accuracy at a $15 \mathrm{~s}$ delay) (Ramos et al., 2003). No significant differences were noted in either the rate of acquisition or in the percentage of correct choices once animals reached criterion as a function of age or adrenocortical status (Fig. 7B,C). Repeated-measures ANOVA revealed main effects for delay interval $\left(F_{(2,32)}=4.95, p=\right.$ $0.01)$, age $\left(F_{(1,16)}=13.60, p=0.002\right)$, adrenocortical status $\left(F_{(1,16)}=5.77, p=0.03\right)$, and the interaction of age and adrenocortical status $\left(F_{(1,16)}=6.10, p=0.03\right)$. Age + high CORT animals displayed deficits in delayed alternation relative to the other three groups at $60 \mathrm{~s}$ ( $p<0.001$ for each) and $120 \mathrm{~s}$ ( $p<0.05$ for each) delay intervals. Aged + low CORT animals also displayed decreased choice accuracy at the $60 \mathrm{~s}$ delay interval relative to young animals ( $p<0.001$ for each), albeit to a lesser extent than the age + high CORT group (Fig. 7C). Comparison of individual values for either the number of training sessions or delay interval as a function of CORT levels failed to reveal any reliable correlation within young or aged groups (data not shown).

\section{Discussion}

In the present study, we have extended previous work showing that aging is marked by a deterioration of prefrontal cognitive functions and accompanying regressive synaptic changes. Although we verified that aging results in reduced dendritic spine density in PL cortical pyramidal neurons, to our knowledge this is the first to show that agerelated dendritic spine alterations in the rat PL can be understood in the context of elevated circulating glucocorticoids and adrenal hypertrophy. As in previous work, digital reconstruction and 3D analysis of spine geometry revealed that losses in the thin spine category were the main contributor to the overall decrease in spine density during aging (Dumitriu et al., 2010; Bloss et al., 
Table 1. Dendritic spine dimensions in layer II/III pyramidal neurons in $\mathrm{PL}^{a}$

\begin{tabular}{|c|c|c|c|c|c|c|c|c|c|}
\hline \multirow[b]{2}{*}{ Dimension } & \multirow[b]{2}{*}{ Range } & \multicolumn{2}{|c|}{ Percentile } & \multicolumn{3}{|c|}{$<25$ th $(\%)$} & \multicolumn{3}{|c|}{$>75$ th $(\%)$} \\
\hline & & 25th & 75th & Y & $A+$ low & $A+$ high & Y & $A+$ low & $A+$ high \\
\hline Head diameter $(\mu \mathrm{m})$ & $0.100-0.895$ & 0.209 & 0.383 & 24.5 & 25.3 & $26.1^{*}$ & 25.4 & $25.8^{*}$ & 25.4 \\
\hline Length $(\mu \mathrm{m})$ & $0.100-2.997$ & 0.808 & 1.718 & 25.6 & $24.0^{*}$ & 24.8 & 23.2 & $28.6^{*}$ & $24.8^{*}$ \\
\hline
\end{tabular}

${ }^{a}$ For each spine morphologic parameter, minimum and maximum values (range), 25 th and 75 th percentiles of the entire population, the percentage of spines below the 25 th percentile, and the percentage of spines above the 75 th percentile are presented for each group. Y, Young; A + low, aged + low CORT; A + high, aged + high CORT.

${ }^{*} p<0.01$ by $\chi^{2}$ goodness-of-fit test (for comparisons of percentiles).
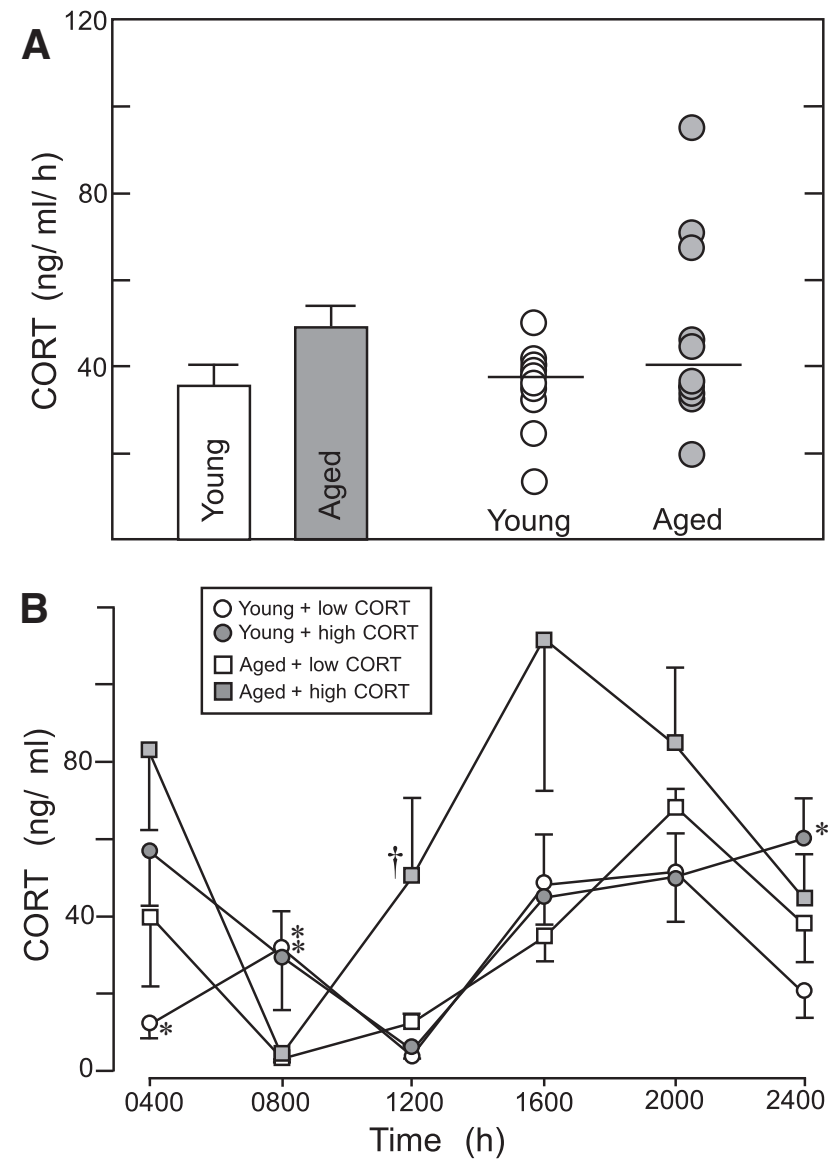

Figure 6. A, Mean + SEM for plasma CORT levels averaged across all six time points sampled (left), and plots of individual values (right). The horizontal lines indicate median values for each age group. $\boldsymbol{B}$, Mean \pm SEM plasma CORT levels in young $(n=10)$ and aged $(n=10)$ animals as a function of HPA status sampled at $4 \mathrm{~h}$ intervals across the light-dark cycle. ${ }^{*} p<0.05$, significantly different from low CORT animals. $t p<0.05$, significantly different from young + high CORT and both low CORT groups. $n=5$ per group.

2011); this effect was either accounted for, or exacerbated by, elevated basal HPA activity. Although some young animals in this study displayed elevated levels of plasma CORT and adrenal hypertrophy, they failed to show any decreases in spine density in immature subtypes.

The findings of this study raise the possibility that young animals with high adrenocortical activity represent a vulnerable subpopulation, whereby the cumulative exposure to higher levels of glucocorticoids over time may render PL neurons susceptible to synaptic compromise that manifests during aging. This interpretation is consistent with evidence that prolonged elevations in circulating glucocorticoids induce structural and functional alterations in hippocampus and impair hippocampal-dependent memory function (Issa et al., 1990; Woolley et al., 1990; Lupien et al., 1998), and the prevention of age-related increases in adreno-
A

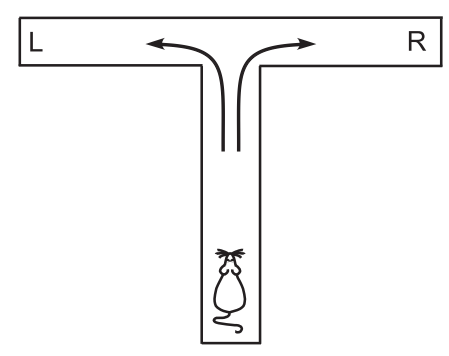

B

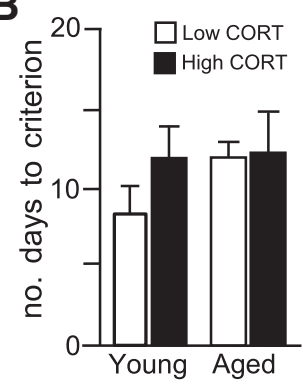

C

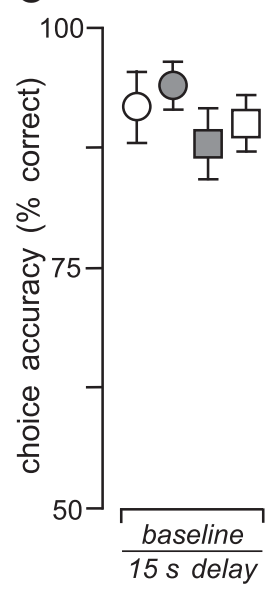

O Young + low CORT $\square$ Aged + low CORT O Young + high CORT $\square$ Aged + high CORT

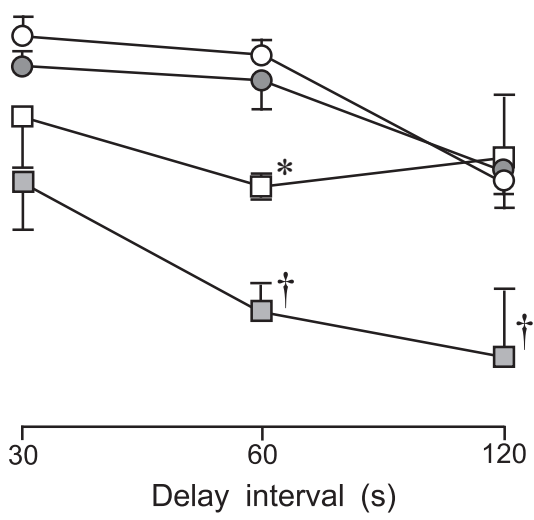

Figure 7. A, Schematic diagram of T maze $(90 \times 65 \mathrm{~cm})$ used for delayed alternation. Rats are placed in the starting location (as shown) and were rewarded for selecting the opposite goal arm (e.g., right, R) from the previous trial (left, L). As the delay interval between each trial is increased, the percentage of correct choices provides a measure of spatial working memory. $\boldsymbol{B}$, Histogram represents the average number of days that animals required to reach an equivalent level of performance in the delayed alternation task ( $>70 \%$ choice accuracy at a 15 s delay). $\boldsymbol{C}$, Graph demonstrating the percentage of correct responses for baseline performance (i.e., at $15 \mathrm{~s}$ delay), and delayed alternation performance. Behavioral impairments were evident in the aged + high CORT group with respect to the other three groups at all three delay intervals $(60$, $120 \mathrm{~s})$, whereas at the $60 \mathrm{~s}$ delay, aged + low CORT animals also showed a significant decrement in performance. Data represent mean $\pm \mathrm{SEM}$ and are based on overall animal averages. ${ }^{*} p<0.05$, significantly different from both young groups. $t p<0.05$, significantly different from both young and aged + low CORT subgroups. $n=5$ animals per group.

cortical output mitigates at least some of these adverse effects (Landfield et al., 1978, 1981). However, this interpretation may be complicated by the fact that PL is also capable of imparting stress-inhibitory influences via cell groups residing within the anterior (or ventrolateral) bed nuclei of the stria terminalis (Radley et al., 2009). Recent evidence suggests that chronic stressinduced dendritic spine plasticity in the PL at the anterior bed nuclei of the stria terminalis HPA-inhibitory pathway may underlie sensitization of adrenocortical output (Radley et al., 2013). Therefore, diminished PL spine density in aging may instead lead to elevated HPA secretory activity. In this scenario, the fact that younger animals with elevated adrenocortical output fail to show 
corresponding decreases in PL spine density suggests that other limbic forebrain (i.e., hippocampus) regions may compensate for prefrontal cortical deficits, whereas impaired hippocampal function during aging may unmask detrimental effects of diminished structural synaptic indices in PL on HPA axis output. To better understand these issues, future studies should address how alterations in hippocampal and prefrontal HPA-inhibitory pathways contribute to elevated HPA output during aging.

Our analysis failed to reveal any relationship between aging or adrenocortical status and dendritic alterations in PL pyramidal neurons. This is consistent with a previous report demonstrating that prefrontal dendritic morphology remains stable across adulthood (Bloss et al., 2010). Thus, when the observations of dendritic morphology and spine density are together, the latter provides a reliable estimate for how aging and adrenocortical status impact the overall population of axospinous synapses in prefrontal neurons. That age-related increases in adrenocortical activity are limited to dendritic spine alterations further indicates that endogenous differences in HPA activity are not sufficient to induce dendritic reorganization in PL neurons. Therefore, regressive structural remodeling in the prefrontal cortex appears to be dependent on more robust stimuli, such as chronic stress exposure or exogenously administered corticosteroids (Wellman, 2001; Cook and Wellman, 2004; Radley et al., 2004; Cerqueira et al., 2005; Perez-Cruz et al., 2007).

Dendritic spines in the cortex are constantly in a labile state and can change shape rapidly in response to a variety of physiological and environmental stimuli (Nimchinsky et al., 2002; Kirov et al., 2004; Yuste and Bonhoeffer, 2004; Holtmaat et al., 2005; Hongpaisan and Alkon, 2007; Liston et al., 2013). Thin spines exhibit a higher degree of plasticity relative to the morphological continuum of spines in the adult cortex (Knott et al., 2006; Bourne and Harris, 2007); they have been implicated in the learning of hippocampal and sensorimotor tasks (Yasumatsu et al., 2008; Yang et al., 2009; Liston et al., 2013), and in optimal prefrontal network functioning and working memory (Kasai et al., 2003; Arnsten et al., 2010). Thin spine loss in the prefrontal cortex has been well documented after chronic stress and aging, and their losses have been hypothesized to account for age-related impairments in cognitive function (Arnsten et al., 2010; Dumitriu et al., 2010; Bloss et al., 2011). Recent evidence has shown that thin spine formation and elimination are tied to the circadian rhythmicity of corticosteroid secretory patterns and are differentially regulated by glucocorticoid and mineralocorticoid receptor-dependent mechanisms (Liston et al., 2013). Hence, even ostensibly subtle fluctuations in basal HPA activity over time may account for large-scale synaptic changes in the prefrontal cortex. Together, our results extend this body of research by highlighting a prominent role for glucocorticoids in driving these synaptic structural alterations, and direct attention to a possible mechanism accounting for differential vulnerability during aging.

At first glance, our inability to identify any group differences in mushroom spines as a function of aging or adrenocortical status appears to be consistent with evidence that attrition of thin, as opposed to mushroom spines, accounts for age- and corticosteroid-mediated functional compromise. However, when we performed population analyses for this subtype, aged animals with high HPA activity were found to have mushroom spines with smaller head diameters than aged animals with lower adrenocortical indices and in both groups of young animals. By contrast, we also found that aged animals bearing low HPA activity displayed larger mushroom spine head diameters in PL neurons than both young groups and aged animals with high HPA activity. When the frequency analysis was expanded to include all subtypes, similar bidirectional shifts were noted in both spine head diameter and length in aged animals as a function of adrenocortical status. That glucocorticoids have recently been shown to modulate spine size via altering activity of the F-actin stabilizing protein, caldesmon (Tanokashira et al., 2012), endorses this as a possible mechanism accounting for the differential regulation of this spine subtype during aging that merits further consideration.

Although rodents lack a granular prefrontal cortical region comparable with that of primates (Wise, 2008), it is generally agreed upon that the rodent mPFC performs working memory functions analogous to those subserved by dorsolateral area 46 in the primate prefrontal cortex (Brown and Bowman, 2002). Our results verified previous work in both rodents and primates that aging results in impaired spatial working memory (for recent reviews, see Arnsten et al., 2010; Hara et al., 2011; Samson and Barnes, 2013), although similar to our structural plasticity data, these effects were largely accounted for in aged animals bearing high HPA activity. The fact that young animals bearing increased HPA activity showed no spatial working memory deficits argues against elevated glucocorticoids per se but instead implicates the cumulative exposure to corticosteroids in prefrontal cognitive impairment. However, it should be noted that aged animals bearing low HPA activity also displayed at least mild deficits in spatial working memory (i.e., 60 s delay interval; Fig. 7C), which suggests that glucocorticoids are not solely responsible for, but instead may exacerbate, age-related cognitive impairment.

One lingering question concerns the extent to which age and HPA-related changes in mushroom spine size vis-à-vis thin spine loss may contribute to spatial working memory deficits. The weight of the evidence supports maintaining the population of thin spines for optimal prefrontal network function and working memory, and their disruption in cognitive deficits (Dumitriu et al., 2010; for review, see Arnsten et al., 2010). By contrast, mushroom spines may be considered as important for mediating longer-term changes in synaptic strength that are more relevant for information storage in different types of memory systems. Nevertheless, subsequent population analyses revealed broader bidirectional effects of CORT during aging, manifested by decreases in spine length and head diameter in aged + high CORT animals, and increases in the proportion of larger and elongated spines in low CORT counterparts. Therefore, regardless of subtype classification, the differential effects of corticosteroids on spine size and/ or length could also provide an additional mechanism accounting for how these hormones modulate prefrontal cognitive impairment during aging. Although these data highlight a new role for glucocorticoids in the attrition of prefrontal functionality during aging, additional work is required to clarify which synaptic changes are critical for maintaining intact cognitive functioning throughout the lifespan.

\section{References}

Arnsten AF, Paspalas CD, Gamo NJ, Yang Y, Wang M (2010) Dynamic network connectivity: a new form of neuroplasticity. Trends Cogn Sci 14:365-375. CrossRef Medline

Barsegyan A, Mackenzie SM, Kurose BD, McGaugh JL, Roozendaal B (2010) Glucocorticoids in the prefrontal cortex enhance memory consolidation and impair working memory by a common neural mechanism. Proc Nat Acad Sci U S A 107:16655-16660. CrossRef Medline

Baxter MG, Gallagher M (1996) Neurobiological substrates of behavioral decline: models and data analytic strategies for individual differences in aging. Neurobiol Aging 17:491-495. CrossRef Medline 
Bloss EB, Janssen WG, McEwen BS, Morrison JH (2010) Interactive effects of stress and aging on structural plasticity in the prefrontal cortex. J Neurosci 30:6726-6731. CrossRef Medline

Bloss EB, Janssen WG, Ohm DT, Yuk FJ, Wadsworth S, Saardi KM, McEwen BS, Morrison JH (2011) Evidence for reduced experience-dependent dendritic spine plasticity in the aging prefrontal cortex. J Neurosci 31: 7831-7839. CrossRef Medline

Bourne J, Harris KM (2007) Do thin spines learn to be mushroom spines that remember? Curr Opin Neurobiol 17:381-386. CrossRef Medline

Boyer C, Schikorski T, Stevens CF (1998) Comparison of hippocampal dendritic spines in culture and in brain. J Neurosci 18:5294-5300. Medline

Brown VJ, Bowman EM (2002) Rodent models of prefrontal cortical function. Trends Neurosci 25:340-343. CrossRef Medline

Cabeza R, Anderson ND, Locantore JK, McIntosh AR (2002) Aging gracefully: compensatory brain activity in high-performing older adults. Neuroimage 17:1394-1402. CrossRef Medline

Cerqueira JJ, Pêgo JM, Taipa R, Bessa JM, Almeida OF, Sousa N (2005) Morphological correlates of corticosteroid-induced changes in prefrontal cortex-dependent behaviors. J Neurosci 25:7792-7800. CrossRef Medline

Cerqueira JJ, Taipa R, Uylings HB, Almeida OF, Sousa N (2007) Specific configuration of dendritic degeneration in pyramidal neurons of the medial prefrontal cortex induced by differing corticosteroid regimens. Cereb Cortex 17:1998-2006. CrossRef Medline

Christoffel DJ, Golden SA, Dumitriu D, Robison AJ, Janssen WG, Ahn HF, Krishnan V, Reyes CM, Han MH, Ables JL, Eisch AJ, Dietz DM, Ferguson D, Neve RL, Greengard P, Kim Y, Morrison JH, Russo SJ (2011) Ikap$\mathrm{paB}$ kinase regulates social defeat stress-induced synaptic and behavioral plasticity. J Neurosci 31:314-321. CrossRef Medline

Cook SC, Wellman CL (2004) Chronic stress alters dendritic morphology in rat medial prefrontal cortex. J Neurobiol 60:236-248. CrossRef Medline

Dickstein DL, Weaver CM, Luebke JI, Hof PR (2013) Dendritic spine changes associated with normal aging. Neuroscience 251:21-32. CrossRef Medline

Divac I (1971) Frontal lobe system and spatial reversal in the rat. Neuropsychologia 9:175-183. CrossRef Medline

Dumitriu D, Hao J, Hara Y, Kaufmann J, Janssen WG, Lou W, Rapp PR, Morrison JH (2010) Selective changes in thin spine density and morphology in monkey prefrontal cortex correlate with aging-related cognitive impairment. J Neurosci 30:7507-7515. CrossRef Medline

Franz CE, O’Brien RC, Hauger RL, Mendoza SP, Panizzon MS, PromWormley E, Eaves LJ, Jacobson K, Lyons MJ, Lupien S, Hellhammer D, Xian H, Kremen WS (2011) Cross-sectional and 35-year longitudinal assessment of salivary cortisol and cognitive functioning: the Vietnam Era twin study of aging. Psychoneuroendocrinology 36:1040-1052. CrossRef Medline

Garrido P (2011) Aging and stress: past hypotheses, present approaches and perspectives. Aging Dis 2:80-99. Medline

Goldman-Rakic PS (1995) Cellular basis of working memory. Neuron 14: 477-485. CrossRef Medline

Hains AB, Vu MA, Maciejewski PK, van Dyck CH, Gottron M, Arnsten AF (2009) Inhibition of protein kinase $C$ signaling protects prefrontal cortex dendritic spines and cognition from the effects of chronic stress. Proc Natl Acad Sci U S A 106:17957-17962. CrossRef Medline

Hara Y, Rapp PR, Morrison JH (2011) Neuronal and morphological bases of cognitive decline in aged rhesus monkeys. Age (Dordr) 34:1051-1073. CrossRef Medline

Holmes A, Wellman CL (2009) Stress-induced prefrontal reorganization and executive dysfunction in rodents. Neurosci Biobehav Rev 33:773783. CrossRef Medline

Holtmaat A, Svoboda K (2009) Experience-dependent structural synaptic plasticity in the mammalian brain. Nat Rev Neurosci 10:647-658. CrossRef Medline

Holtmaat AJ, Trachtenberg JT, Wilbrecht L, Shepherd GM, Zhang X, Knott GW, Svoboda K (2005) Transient and persistent dendritic spines in the neocortex in vivo. Neuron 45:279-291. CrossRef Medline

Hongpaisan J, Alkon DL (2007) A structural basis for enhancement of longterm associative memory in single dendritic spines regulated by PKC. Proc Natl Acad Sci U S A 104:19571-19576. CrossRef Medline

Issa AM, Rowe W, Gauthier S, Meaney MJ (1990) Hypothalamic-pituitaryadrenal activity in aged, cognitively impaired and cognitively unimpaired rats. J Neurosci 10:3247-3254. Medline

Kasai H, Matsuzaki M, Noguchi J, Yasumatsu N, Nakahara H (2003)
Structure-stability-function relationships of dendritic spines. Trends Neurosci 26:360-368. CrossRef Medline

Kirov SA, Petrak LJ, Fiala JC, Harris KM (2004) Dendritic spines disappear with chilling but proliferate excessively upon rewarming of mature hippocampus. Neuroscience 127:69-80. CrossRef Medline

Knott GW, Holtmaat A, Wilbrecht L, Welker E, Svoboda K (2006) Spine growth precedes synapse formation in the adult neocortex in vivo. Nat Neurosci 9:1117-1124. CrossRef Medline

Landfield PW, Waymire JC, Lynch G (1978) Hippocampal aging and adrenocorticoids: quantitative correlations. Science 202:1098-1102. CrossRef Medline

Landfield PW, Baskin RK, Pitler TA (1981) Brain aging correlates: retardation by hormonal-pharmacological treatments. Science 214:581-584. CrossRef Medline

Li G, Cherrier MM, Tsuang DW, Petrie EC, Colasurdo EA, Craft S, Schellenberg GD, Peskind ER, Raskind MA, Wilkinson CW (2006) Salivary cortisol and memory function in human aging. Neurobiol Aging 27:1705-1714. CrossRef Medline

Liston C, Gan WB (2011) Glucocorticoids are critical regulators of dendritic spine development and plasticity in vivo. Proc Natl Acad Sci U S A 108: 16074-16079. CrossRef Medline

Liston C, Miller MM, Goldwater DS, Radley JJ, Rocher AB, Hof PR, Morrison JH, McEwen BS (2006) Stress-induced alterations in prefrontal cortical dendritic morphology predict selective impairments in perceptual attentional set-shifting. J Neurosci 26:7870-7874. CrossRef Medline

Liston C, Cichon JM, Jeanneteau F, Jia Z, Chao MV, Gan WB (2013) Circadian glucocorticoid oscillations promote learning-dependent synapse formation and maintenance. Nat Neurosci 16:698-705. CrossRef Medline

Liu RJ, Aghajanian GK (2008) Stress blunts serotonin- and hypocretinevoked EPSCs in prefrontal cortex: role of corticosterone-mediated apical dendritic atrophy. Proc Natl Acad Sci U S A 105:359-364. CrossRef Medline

Lupien SJ, de Leon M, de Santi S, Convit A, Tarshish C, Nair NP, Thakur M, McEwen BS, Hauger RL, Meaney MJ (1998) Cortisol levels during human aging predict hippocampal atrophy and memory deficits. Nat Neurosci 1:69-73. CrossRef Medline

Lupien SJ, Gillin CJ, Hauger RL (1999) Working memory is more sensitive than declarative memory to the acute effects of corticosteroids: a doseresponse study in humans. Behav Neurosci 113:420-430. CrossRef Medline

Lupien S, Lecours AR, Lussier I, Schwartz G, Nair NP, Meaney MJ (1994) Basal cortisol levels and cognitive deficits in human aging. J Neurosci 14:2893-2903. Medline

Matsuzaki M, Ellis-Davies GC, Nemoto T, Miyashita Y, Iino M, Kasai H (2001) Dendritic spine geometry is critical for AMPA receptor expression in hippocampal CAl pyramidal neurons. Nat Neurosci 4:10861092. CrossRef Medline

McEwen BS (1998) Protective and damaging effects of stress mediators. N Engl J Med 338:171-179. CrossRef Medline

McEwen BS, Morrison JH (2013) The brain on stress: vulnerability and plasticity of the prefrontal cortex over the life course. Neuron 79:16-29. CrossRef Medline

Mizoguchi K, Ikeda R, Shoji H, Tanaka Y, Maruyama W, Tabira T (2009) Aging attenuates glucocorticoid negative feedback in rat brain. Neuroscience 159:259-270. CrossRef Medline

Morrison JH, Baxter MG (2012) The ageing cortical synapse: hallmarks and implications for cognitive decline. Nat Rev Neurosci 13:240-250. CrossRef Medline

Nimchinsky EA, Sabatini BL, Svoboda K (2002) Structure and function of dendritic spines. Annu Rev Physiol 64:313-353. CrossRef Medline

Perez-Cruz C, Müller-Keuker JI, Heilbronner U, Fuchs E, Flugge G (2007) Morphology of pyramidal neurons in the rat prefrontal cortex: lateralized dendritic remodeling by chronic stress. Neural Plast 2007:46276. CrossRef Medline

Peters A, Sethares C, Luebke JI (2008) Synapses are lost during aging in the primate prefrontal cortex. Neuroscience 152:970-981. CrossRef Medline

Petrak LJ, Harris KM, Kirov SA (2005) Synaptogenesis on mature hippocampal dendrites occurs via filopodia and immature spines during blocked synaptic transmission. J Comp Neurol 484:183-190. CrossRef Medline

Radley JJ, Sisti HM, Hao J, Rocher AB, McCall T, Hof PR, McEwen BS, 
Morrison JH (2004) Chronic behavioral stress induces apical dendritic reorganization in pyramidal neurons of the medial prefrontal cortex. Neuroscience 125:1-6. CrossRef Medline

Radley JJ, Rocher AB, Janssen WG, Hof PR, McEwen BS, Morrison JH (2005) Reversibility of apical dendritic retraction in the rat medial prefrontal cortex following repeated stress. Exp Neurol 196:199-203. CrossRef Medline

Radley JJ, Rocher AB, Miller M, Janssen WG, Liston C, Hof PR, McEwen BS, Morrison JH (2006) Repeated stress induces dendritic spine loss in the rat medial prefrontal cortex. Cereb Cortex 16:313-320. CrossRef Medline

Radley JJ, Rocher AB, Rodriguez A, Ehlenberger DB, Dammann M, McEwen BS, Morrison JH, Wearne SL, Hof PR (2008) Repeated stress alters dendritic spine morphology in the rat medial prefrontal cortex. J Comp Neurol 507:1141-1150. CrossRef Medline

Radley JJ, Gosselink KL, Sawchenko PE (2009) A discrete GABAergic relay mediates medial prefrontal cortical inhibition of the neuroendocrine stress response. J Neurosci 29:7330-7340. CrossRef Medline

Radley JJ, Anderson RM, Hamilton BA, Alcock JA, Romig-Martin SA (2013) Chronic stress-induced alterations of dendritic spine subtypes predict functional decrements in an hypothalamo-pituitary-adrenal-inhibitory prefrontal circuit. J Neurosci 33:14379-14391. CrossRef Medline

Ramos BP, Birnbaum SG, Lindenmayer I, Newton SS, Duman RS, Arnsten AF (2003) Dysregulation of protein kinase a signaling in the aged prefrontal cortex: new strategy for treating age-related cognitive decline. Neuron 40:835-845. CrossRef Medline

Rapp PR, Amaral DG (1992) Individual differences in the cognitive and neurobiological consequences of normal aging. Trends Neurosci 15:340 345. CrossRef Medline

Rodriguez A, Ehlenberger DB, Hof PR, Wearne SL (2006) Rayburst sampling, an algorithm for automated three-dimensional shape analysis from laser scanning microscopy images. Nat Protoc 1:2152-2161. CrossRef Medline

Rowe JW, Kahn RL (1987) Human aging: usual and successful. Science 237: 143-149. CrossRef Medline

Samson RD, Barnes CA (2013) Impact of aging brain circuits on cognition. Eur J Neurosci 37:1903-1915. CrossRef Medline

Sapolsky RM (1992) Stress, the aging brain, and the mechanisms of neuron death. Cambridge, MA: Massachusetts Institute of Technology.

Tanokashira D, Morita T, Hayashi K, Mayanagi T, Fukumoto K, Kubota Y, Yamashita T, Sobue K (2012) Glucocorticoid suppresses dendritic spine development mediated by down-regulation of caldesmon expression. J Neurosci 32:14583-14591. CrossRef Medline

Wellman CL (2001) Dendritic reorganization in pyramidal neurons in medial prefrontal cortex after chronic corticosterone administration. J Neurobiol 49:245-253. CrossRef Medline

Wise SP (2008) Forward frontal fields: phylogeny and fundamental function. Trends Neurosci 31:599-608. CrossRef Medline

Woolley CS, Gould E, McEwen BS (1990) Exposure to excess glucocorticoids alters dendritic morphology of adult hippocampal pyramidal neurons. Brain Res 531:225-231. CrossRef Medline

Yang G, Pan F, Gan WB (2009) Stably maintained dendritic spines are associated with lifelong memories. Nature 462:920-924. CrossRef Medline

Yasumatsu N, Matsuzaki M, Miyazaki T, Noguchi J, Kasai H (2008) Principles of long-term dynamics of dendritic spines. J Neurosci 28:1359213608. CrossRef Medline

Yuste R, Bonhoeffer T (2004) Genesis of dendritic spines: insights from ultrastructural and imaging studies. Nat Rev Neurosci 5:24-34. CrossRef Medline

Zhang TY, Meaney MJ (2010) Epigenetics and the environmental regulation of the genome and its function. Annu Rev Psychol 61:439-466. CrossRef Medline 